\title{
Genetic Analysis of Male and Female Fertility After Artificial Insemination in Sheep: Comparison of Single-Trait and Joint Models
}

\author{
I. David, ${ }^{\star 1}$ L. Bodin, ${ }^{*}$ G. Lagriffoul, $\dagger$ C. Leymarie, ${ }^{*}$ E. Manfredi, ${ }^{*}$ and C. Robert-Granié ${ }^{\star}$ \\ *Station d'Amélioration Génétique des Animaux, Institut National de la Recherche Agronomique (INRA) BP 52627, \\ 31326 Castanet-Tolosan Cedex, France \\ †Institut de l'élevage-ANIO, BP 42 118, 31321 Castanet Tolosan Cedex, France
}

\begin{abstract}
The outcome of an insemination depends on male and female fertility. Nevertheless, few studies have incorporated genetic evaluation of these 2 traits jointly. The aim of this work was to compare genetic parameter estimates of male and female fertility defined as success or failure to artificial insemination (AI), using 8 different models. The first 2 models were simple repeatability models studying fertility of one sex and ignoring any information of the other. Models 3 and 4 took into account the information of the other sex by the inclusion of its random permanent environmental effect, whereas models 5 and 6 included fixed effects of the other sex. Models 7 and 8 were joint genetic evaluation models of male and female fertility ignoring or considering genetic correlation. Data were composed of 147,018 AI of the Manech Tête Rousse breed recorded from 2000 to 2004 corresponding to 79,352 ewes and $963 \mathrm{rams}$. The pedigree file included 120,989 individuals. Variance component estimates from the different models were quite similar; heritabilities varied from 0.050 to 0.053 for female fertility and were near 0.003 for male fertility. Correlations among estimated breeding values in the same sex using different models were higher than 0.99 . The genetic correlation between male and female fertility was not significantly different from 0 . These results show that for French dairy sheep with extensive use of AI, estimation of breeding values for male and female fertility might be implemented with quite simple models.
\end{abstract}

Key words: fertility, joint modeling, sheep

\section{INTRODUCTION}

The success of ovine AI depends on many factors. The male must produce and ejaculate normal fertile spermatozoa. The female must produce, store, and ovu-

Received November 16, 2006.

Accepted March 22, 2007.

${ }^{1}$ Corresponding author: Ingrid.David@toulouse.inra.fr late normal oocytes and provide a reproductive tract compatible with sperm transport, capacitation, and fertilization of the oocytes. The female must ensure embryo and fetal development and birth of progeny. Finally, the corresponding fetus must be viable. Because insemination is artificial, natural sexual behavior is absent and the male and female reproductive events have to be carefully synchronized to minimize the gamete waiting time before fertilization occurs. That also supposes that the sperm is correctly processed and transported and that insemination practices are sound.

Under the simplest biological considerations, AI success may be viewed as a combination of 2 main traits: one relative to the female (i.e., female fertility), the second relative to the male (i.e., male fertility). The same observation (AI success or failure) can be analyzed with respect to female fertility, male fertility or both. However, most genetic fertility studies generally consider only one of these 2 traits and model the AI response by fitting its specific genetic effect and the related environmental factors. Studies related to livestock male or female fertility have been conducted in many species and in many environmental conditions (Nadarajah et al., 1988; Boichard and Manfredi, 1994; Matos et al., 1997b; Ranberg et al., 2003; GonzalezRecio and Alenda, 2005). They consider several types of fertility variables, ranging from binary (e.g., nonreturn rate after 60 or $90 \mathrm{~d}$ or confirmed pregnancy) to continuous (e.g., calving interval or number of AI services per conception response). The results generally agree and indicate that, whatever the trait, heritabilities are very low $(<0.10)$. Moreover, variance components associated with male fertility are generally smaller than those for female fertility.

The purpose of this study was to evaluate the impact of including all information relative to the $\mathrm{AI}$ event on variance component and breeding value estimations in sheep. This approach is possible because, in the French sheep industry, each on-farm recorded insemination can be matched to the corresponding ejaculate produced at the $\mathrm{AI}$ center and to the corresponding outcome, 
Table 1. Distribution of the number of inseminations per animal

\begin{tabular}{lcccc}
\hline \multicolumn{2}{c}{ Female } & & \multicolumn{2}{c}{ Male } \\
\cline { 5 - 5 } \cline { 5 - 5 } $\begin{array}{l}\text { Number of } \\
\text { inseminations }\end{array}$ & $\begin{array}{c}\text { Number } \\
\text { of females } \\
(\%)\end{array}$ & & $\begin{array}{c}\text { Number of } \\
\text { inseminations }\end{array}$ & $\begin{array}{c}\text { Number } \\
\text { of males } \\
(\%)\end{array}$ \\
\hline 1 & $37,997(48)$ & & $<60$ & $219(23)$ \\
2 & $22,433(28)$ & & $60-180$ & $553(58)$ \\
3 & $12,736(16)$ & & $180-300$ & $87(9)$ \\
4 & $4,983(6.5)$ & & $300-420$ & $37(3)$ \\
5 & $1,203(1.5)$ & $>420$ & $67(7)$ \\
\hline
\end{tabular}

which is a binary response of success (1) or failure (0) observed at lambing.

\section{MATERIALS AND METHODS}

\section{Data}

Records of inseminations from 2000 to 2004 were provided by the Association Nationale des centres d'Insémination Ovine (ANIO). A small part (4\%) of the initial data set containing missing records for the insemination result (ewes sold, dying before lambing, error in the data) were discarded. The final data file included 147,018 AI records of the Manech Tête Rousse breed located in southwestern France. Manech Tête Rousse ewes are managed in an annual lambing system. Each year depending on the breeding scheme, the breeders choose which ewes to inseminate. The ewes receive one single synchronization treatment (fluorogestone acetate vaginal sponge inserted for $14 \mathrm{~d}$, pregnant mares' serum gonadotropin injection at withdrawal) and are inseminated without regard to estrus expression. Inseminated females are systematically exposed to rams for $6 \mathrm{~d}$ after insemination to ensure fecundation by natural mating. The other females are naturally mated without synchronization. Because there is no pregnancy test, the date of lambing is used to determine the fertile estrus (after insemination or natural mating). Ejaculates were collected from 963 rams using artificial vagina, and 79,352 different ewes were inseminated. After quality processing (volume, concentration, and motility); semen with a motility higher than 4 was diluted (dose concentration $=1.4$ or $1.6 \times 10^{6}$ spermato$\mathrm{zoa} / \mathrm{mL}$ ) and stored at $4^{\circ} \mathrm{C}$ in a $0.25 \mathrm{~mL}$ straw until insemination a few hours later. The distributions of the number of inseminations for rams and ewes are in Table 1. The pedigree file (the first animal was born in 1958) included 120,989 individuals. For each insemination, a large list of information was recorded. The corresponding potential risk factors may be grouped into 3 categories. These were female (synchronization, reproductive, and productive career, etc.), male (sperm characteristics, collection, etc.), and nonsex-specific effects which were related to the insemination (operator, interval collection-AI, etc.) or common to all previous categories (year, season, herd).

\section{Methods}

Fertility was defined as the binary result of an insemination, considered a success $(\mathrm{y}=1)$ when lambing occurred 144 to $158 \mathrm{~d}$ after insemination or a failure $(\mathrm{y}=$ 0 ). The percentage of successful inseminations was $57 \%$. Eight linear animal models were used to study the insemination results. Fixed effects and all 2-way interactions with biological meaning were selected one at a time by comparing nested models with a likelihood ratio test. Models were fitted using the mixed procedure of SAS 8.1 (SAS, version 8, 1999) and the maximum likelihood estimation method. After model selection, female effects retained were age, synchronization on the previous year $(0=$ no, $1=$ yes $)$, total number of synchronizations during the female reproductive life, time interval between previous lambing and insemination, lactation status ( $0=$ dry, $1=$ lactating $)$ at time of insemination, milk quantity produced during the previous year expressed as quartiles within each herd $\times$ year. Male effects retained were motility and dilution rate of the semen (ejaculate concentration/dose concentration). Nonsex specific effects were the inseminator, the interaction herd $\times$ year nested within inseminator considered as random effects, and the interaction of year and season considered as a fixed effect.

The first 2 and simplest models focused on the estimation of the fertility trait of only one sex (the male in model 1 , the female in model 2) without introducing any terms related to the contributions from the other sex. The models included the fixed and random effects that are not sex specific as well as the fixed effects, the random permanent environmental and the genetic effects associated with the sex being considered by the respective model.

$$
\begin{gathered}
\text { Model 1: } \boldsymbol{y}=\boldsymbol{X}_{\boldsymbol{c}} \boldsymbol{\beta}_{\boldsymbol{c}}+\boldsymbol{K c}+\boldsymbol{L h}+\boldsymbol{X}_{\boldsymbol{m}} \boldsymbol{\beta}_{\boldsymbol{m}} \\
+\boldsymbol{Z}_{\boldsymbol{m}} \boldsymbol{u}_{\boldsymbol{m}}+\boldsymbol{W}_{\boldsymbol{m}} \boldsymbol{p}_{m}+\varepsilon
\end{gathered}
$$

and

$$
\begin{gathered}
\text { model 2: } \boldsymbol{y}=\boldsymbol{X}_{\boldsymbol{c}} \boldsymbol{\beta}_{\boldsymbol{c}}+\boldsymbol{K} \boldsymbol{c}+\boldsymbol{L h}+\boldsymbol{X}_{\boldsymbol{f}} \boldsymbol{\beta}_{\boldsymbol{f}} \\
+\boldsymbol{Z}_{\boldsymbol{f}} \boldsymbol{u}_{f}+\boldsymbol{W}_{f} \boldsymbol{p}_{f}+\varepsilon
\end{gathered}
$$

where $\boldsymbol{y}$ is the vector of the binary result of insemination, $\boldsymbol{\beta}_{\boldsymbol{f}} \boldsymbol{\beta}_{\boldsymbol{m}}$, and $\boldsymbol{\beta}_{\boldsymbol{c}}$ are vectors of fixed effects related to the female, the male, or common to both sexes, respectively; $\boldsymbol{u}_{\boldsymbol{f}}$ and $\boldsymbol{u}_{\boldsymbol{m}}$ are vectors of female and male random genetic effects, respectively; $\boldsymbol{p}_{\boldsymbol{f}}$ and $\boldsymbol{p}_{\boldsymbol{m}}$ are vectors of 
female and male random permanent environmental effects; $\boldsymbol{c}$ and $\boldsymbol{h}$ are the random vectors of inseminator and herd $\times$ year intrainseminator effects, respectively; $\varepsilon$ is the vector of residuals in each model; and $\boldsymbol{X}_{\boldsymbol{f}}, \boldsymbol{X}_{\boldsymbol{m}}$, $\boldsymbol{X}_{\boldsymbol{c}}, \boldsymbol{Z}_{f}, \boldsymbol{Z}_{\boldsymbol{m}}, \boldsymbol{W}_{\boldsymbol{f}}, \boldsymbol{W}_{\boldsymbol{m}}, \boldsymbol{K}$, and $\boldsymbol{L}$ are the corresponding known incidence matrices. All random effects are distributed as centered normal distributions with variance covariance matrices equal to $\boldsymbol{A} \boldsymbol{\sigma}_{i}^{2}$ for the genetic effects $i\left(i=u_{f}\right.$ or $\left.u_{m}\right)$, and $\boldsymbol{I}_{j} \sigma_{j}^{2}$ for the other random effects $j$ $\left(j=c, h, p_{f}, p_{m}\right.$, or $\varepsilon$ ), where $\boldsymbol{A}$ is the known relationship matrix, $\boldsymbol{I}_{j}$ are identity matrices of appropriate order; and $\sigma_{i}^{2}$ and $\sigma_{j}^{2}$ are the corresponding variances associated with $i$ and $j$. Random effects are assumed to be independent of each other. The same notations will be used in all models, and the same assumptions for random effects will be used in models 1 to 7 .

Models 1 and 2 ignored that conception is a function of both the male and female. Fitting the random effect of the inseminated female in model 1 and the random effect of the service male in model 2 may improve the predictive ability of the models. Taking into account these effects, the models became

$$
\begin{aligned}
\operatorname{model~3:y=} & \boldsymbol{X}_{\boldsymbol{c}} \boldsymbol{\beta}_{\boldsymbol{c}}+\boldsymbol{K} \boldsymbol{c}+\boldsymbol{L} \boldsymbol{h}+\boldsymbol{X}_{\boldsymbol{m}} \boldsymbol{\beta}_{\boldsymbol{m}}+\boldsymbol{Z}_{\boldsymbol{m}} \boldsymbol{u}_{\boldsymbol{m}} \\
& +\boldsymbol{W}_{\boldsymbol{m}} \boldsymbol{p}_{m}+\boldsymbol{W}_{f} \boldsymbol{p}_{f}+\varepsilon
\end{aligned}
$$

and

$$
\begin{aligned}
\operatorname{model} 4: \boldsymbol{y} & =\boldsymbol{X}_{\boldsymbol{c}} \boldsymbol{\beta}_{\boldsymbol{c}}+\boldsymbol{K} \boldsymbol{c}+\boldsymbol{L h}+\boldsymbol{X}_{\boldsymbol{f}} \boldsymbol{\beta}_{f}+\boldsymbol{Z}_{f} \boldsymbol{u}_{f} \\
& +\boldsymbol{W}_{f} \boldsymbol{p}_{f}+\boldsymbol{W}_{\boldsymbol{m}} \boldsymbol{p}_{m}+\varepsilon
\end{aligned}
$$

Model 4, ignoring male fixed effects, assumed that the service male effect is constant over the lifetime of the male. However, because selection of fixed effects in our data showed that motility and dilution rate of the semen had a significant influence on the insemination result, this assumption seemed unrealistic. Symmetric reasoning can be made for the study of AI result on the male side in model 3. So, adding male fixed effects in model 4 , and conversely adding female fixed effects in model 3 may be more appropriate. The extended models are

$$
\begin{gathered}
\text { model 5: } \boldsymbol{y}=\boldsymbol{X}_{\boldsymbol{c}} \boldsymbol{\beta}_{\boldsymbol{c}}+\boldsymbol{K} \boldsymbol{c}+\boldsymbol{L h}+\boldsymbol{X}_{\boldsymbol{m}} \boldsymbol{\beta}_{m}+\boldsymbol{Z}_{m} \boldsymbol{u}_{m} \\
+\boldsymbol{W}_{\boldsymbol{m}} \boldsymbol{p}_{m}+\boldsymbol{W}_{f} \boldsymbol{p}_{f}+\boldsymbol{X}_{f} \boldsymbol{\beta}_{f}+\varepsilon
\end{gathered}
$$

and

$$
\begin{gathered}
\text { model 6: } \boldsymbol{y}=\boldsymbol{X}_{\boldsymbol{c}} \boldsymbol{\beta}_{\boldsymbol{c}}+\boldsymbol{K} \boldsymbol{c}+\boldsymbol{L h}+\boldsymbol{X}_{\boldsymbol{f}} \boldsymbol{\beta}_{f}+\boldsymbol{Z}_{f} \boldsymbol{u}_{f} \\
+\boldsymbol{W}_{f} \boldsymbol{p}_{f}+\boldsymbol{X}_{m} \boldsymbol{\beta}_{m}+\boldsymbol{W}_{m} \boldsymbol{p}_{m}+\varepsilon
\end{gathered}
$$

The random effect corresponding to the inseminated female in model 5 and the random service male effect in model 6 gather the genetic and the permanent environmental effects of the female and the male, respectively. With the introduction of the genetic relationships, these effects attached to each sex could be split in their respective genetic and permanent components leading to the common joint model 7 . This joint model describes the insemination result by a set of genetic and environmental components, which gave the same importance to both sexes.

$$
\begin{gathered}
\text { Model 7: } \boldsymbol{y}=\boldsymbol{X}_{\boldsymbol{c}} \boldsymbol{\beta}_{\boldsymbol{c}}+\boldsymbol{K c}+\boldsymbol{L h}+\boldsymbol{X}_{\boldsymbol{m}} \boldsymbol{\beta}_{\boldsymbol{m}}+\boldsymbol{Z}_{\boldsymbol{m}} \boldsymbol{u}_{\boldsymbol{m}} \\
+\boldsymbol{W}_{\boldsymbol{m}} \boldsymbol{p}_{m}+\boldsymbol{X}_{f} \boldsymbol{\beta}_{f}+\boldsymbol{Z}_{f} \mathbf{u}_{f}+\boldsymbol{W}_{f} \boldsymbol{p}_{f}+\varepsilon
\end{gathered}
$$

model 7 assumes that male and female fertility are genetically independent. This assumption was relaxed in model 8 where covariance between male and female fertility genetic effects is considered to potentially be different from zero.

All models were fitted using ASREML software (Gilmour et al., 2002). In all models, heritability was computed as $\sigma_{u_{m}}^{2} /\left(\sigma_{u_{m}}^{2}+\sigma_{p_{m}}^{2}+\sigma_{\varepsilon}^{2}\right)$ for male fertility, $\sigma_{u_{f}}^{2} /\left(\sigma_{u_{f}}^{2}+\sigma_{p_{f}}^{2}+\sigma_{\varepsilon}^{2}\right)$ for female fertility; repeatability was computed as $\left(\sigma_{u_{m}}^{2}+\sigma_{p_{m}}^{2}\right) /\left(\sigma_{u_{m}}^{2}+\sigma_{p_{m}}^{2}+\sigma_{\varepsilon}^{2}\right)$ for male fertility, $\left(\sigma_{u_{f}}^{2}+\sigma_{p_{f}}^{2}\right) /\left(\sigma_{u_{f}}^{2}+\sigma_{p_{f}}^{2}+\sigma_{\varepsilon}^{2}\right)$ for female fertility.

Except in the case where fixed effects were added, nested models were compared using the restricted likelihood ratio test. When the model comparison corresponded to a test of parameter on the boundary of parameter space (test of variance to 0 ), the distribution of this test statistic under the null hypothesis is a 50:50 mixture of $\chi_{\boldsymbol{q}}^{2}$ and $\chi_{\boldsymbol{q}+\mathbf{1}}^{2}$ distributions (Morrell, 1998), where $q$ is the number of random effects in the reduced model (residual effect excluded).

\section{RESULTS AND DISCUSSION}

Even if the outcome of an insemination is a binary variable, we used analysis methods for continuous data, which are not theoretically optimal. The suitable methodology is the threshold model introduced by Wright (1934) and developed by several authors (Gianola, 1982; Harville and Mee, 1984). Nevertheless, some studies showed that the estimates of heritability or breeding values from linear and threshold models are highly correlated (Hoeschele and Tier, 1995; Matos et al., 1997a,b; Ramirez-Valverde et al., 2001). The difference between these methodologies has been shown to be negligible when the incidence of the binary response was between 25 and 75\% (Meijering and Gianola, 1985), when there are sufficient $(>50)$ progeny records per sire (Ramirez-Valverde et al., 2001), and when the incidence is lowly variable among subclasses of data defined by 
fixed effects. The insemination results analyzed in this study provided favorable conditions for using the continuous approximation. The percentage of successful inseminations was equal to $57 \%$, and $85 \%$ of the sires had more than 50 male records, but only $24 \%$ of the sires had more than 50 female records. To verify the consequences of the continuous approximation, an analysis was performed using the MCMC method for model 8 under the threshold model assumption but not for all models due to long computing time $(19 \mathrm{~d})$. The estimation of the heritabilities under the p-scale (observed scale) obtained with the threshold model were quite similar to those using the linear approximation and the correlation between EBV obtained under the linear and the threshold model assumptions was 0.99 for female fertility and 0.96 for male fertility. The results obtained with the MCMC method are presented in the Appendix.

Variance components and genetic parameters estimated with models 1 to 8 are in Table 2. Although there was significantly better fit as models increased in complexity from model 1 to 7 , the variance components obtained with the different models were quite similar. The correlations between EBV estimated in model 8 and EBV estimated in other models for male fertility varied from 0.90 to 0.92 . All other correlations between EBV or between fertility ability (EBV + permanent environmental effect) among comparable models were higher than 0.99 for female and male fertility. These results indicate that for French dairy sheep, estimation of the genetic parameters could be implemented with quite simple models. Heritability estimates for female fertility with the different models were low, about 5\%, and in the middle of the range of heritability estimated in previous studies from 1\% (Kadarmideen et al., 2000) to $10 \%$ (Matos et al., 1997a). Female repeatability estimates were also small, ranging from 10 to $13 \%$. Few studies estimate repeatability for female fertility because generally one record per female is used. Heritabilities and repeatabilities obtained for male fertility were very low (about 0.3 and $0.8 \%$, respectively). They were smaller than heritabilities estimated in some studies (Nadarajah et al., 1988; Varona and Noguera, 2001; Piles et al., 2005), but similar for male sources of variation obtained in studies that did not evaluate the genetic portion of male fertility (from 0.2 to $0.8 \%$; Boichard and Manfredi, 1994; Weigel and Rekaya, 2000; Ranberg et al., 2003; Averill et al., 2004).

Models 1 and 2 corresponded to the male or female fertility ignoring information of the other sex. Similar models have been used by several authors (Matos et al., 1997b; Nadarajah et al., 1988; Kadarmideen et al., 2000; Andersen-Ranberg et al., 2005; Gonzalez-Recio and Alenda, 2005). In models 1 and 2, 97 and 84\% of the initial variance remained unexplained, respectively.

Including the female random environmental effect in the simplest model for studying male fertility (models 3 vs. 1$)$ improved the model $(P<0.001)$ and reduced the residual variance $(0.20$ vs. 0.23$)$ but there was no real change in the estimates for male fertility heritability $(0.32$ vs. $0.28 \%)$ or repeatability ( 0.84 vs. $0.72 \%)$. Estimated breeding values were similar between the 2 models (correlation $=0.99$ ). In this breed, on average a male inseminated 152 females according to a design that tends to optimize the breeding evaluation and genetic progress. Therefore, these females may be considered as a random sample of the population, which explains that male EBV did not change from model 1 to 3 .

In contrast, females have few records. Nevertheless, including the male random effect in the simplest female fertility model (model 4 vs. 2) did not change female EBV because the rams' permanent environmental effect variance was very small (0.002). A similar result has been found by Ranberg et al. (2003). This kind of model is frequently used to study female fertility (Boichard and Manfredi, 1994; Weigel and Rekaya, 2000; Ranberg et al., 2003; Donoghue et al., 2004; Spangler et al., 2006).

Including female (model 5) or male (model 6) fixed effects in models 3 or 4 , respectively, did not affect genetic effect estimates for the other sex because, even if these fixed effects were significant, they were generally small and did not change the residual variance estimate (about 0.20 ). Such models are not frequently used because the situation in which information of fixed effects of both sexes can be matched is rare.

Including the genetic relationship information for studying female (models 7 vs. 5) or male fertility trait (models 7 vs. 6) did not change variance component estimates, but model 7 fit the data better than models 5 or $6(P<0.001$ and $P=0.02$, respectively). Similar joint genetic evaluations have already been proposed by several authors (Varona and Noguera, 2001; Ranberg et al., 2003; Piles et al., 2005).

Finally, the likelihood ratio test comparing model 8 with model 7 showed that the correlation between male and female fertility, estimated at 0.23 , did not differ significantly from $0(P=0.16)$. A large range of estimates of correlations between male and female fertility has been reported in the literature [from -0.5 by Varona and Noguera (2001) to 0.7 by Piles et al. (2005)]. This correlation is difficult to estimate because of the very small male genetic variance and is probably associated with a large standard error (not calculated in this study), which may explain this wide range.

Because of the large residual variance, estimated heritabilities were small for both traits. Nevertheless, sig- 
Table 2. Variance components and genetic parameter (SE) estimates with the different models

\begin{tabular}{|c|c|c|c|c|c|c|c|c|}
\hline \multirow[b]{2}{*}{ Item } & \multicolumn{8}{|c|}{ Model } \\
\hline & 1 & 2 & 3 & 4 & 5 & 6 & 7 & 8 \\
\hline $\begin{array}{l}\text { Fixed effect }{ }^{1} \\
\text { Perm. env. }{ }^{2} \\
\text { Genetic effect }{ }^{3} \\
-2 L^{4}\end{array}$ & $\begin{array}{r}\mathrm{M} \\
\mathrm{M} \\
\mathrm{M} \\
-64,669\end{array}$ & $\begin{array}{r}\mathrm{F} \\
\mathrm{F} \\
\mathrm{F} \\
-67,504\end{array}$ & $\begin{array}{r}\mathrm{M} \\
\mathrm{M}+\mathrm{F} \\
\mathrm{M} \\
-66,286\end{array}$ & $\begin{array}{r}\mathrm{F} \\
\mathrm{M}+\mathrm{F} \\
\mathrm{F} \\
-67,887\end{array}$ & $\begin{array}{r}M+F \\
M+F \\
M \\
-67,379\end{array}$ & $\begin{array}{r}M+F \\
M+F \\
F \\
-68,012\end{array}$ & $\begin{array}{r}M+F \\
M+F \\
M+F \\
-68,026\end{array}$ & $\begin{array}{r}M+F \\
M+F \\
M+F \\
-68,028\end{array}$ \\
\hline$P$-value & & & $<0.001^{5}$ & $<0.001^{6}$ & & & $\begin{array}{r}0.023^{7} \\
<0.001^{8}\end{array}$ & $0.157^{9}$ \\
\hline$\sigma_{\varepsilon}^{2}$ & 0.2310 & 0.2059 & 0.1995 & 0.2036 & 0.2039 & 0.2034 & 0.2037 & 0.2037 \\
\hline$\sigma_{p m}^{2}$ & 0.0010 & - & 0.0010 & 0.0020 & 0.0010 & 0.0016 & 0.0010 & 0.0010 \\
\hline$\sigma_{u m}^{2}$ & 0.0007 & - & 0.0006 & - & 0.0006 & - & 0.0007 & 0.0006 \\
\hline$\sigma_{p f}^{2}$ & - & 0.0136 & 0.0316 & 0.0139 & 0.0242 & 0.0138 & 0.0136 & 0.0135 \\
\hline$\sigma_{u f}^{2}$ & - & 0.0116 & - & 0.0121 & - & 0.0121 & 0.0120 & 0.0120 \\
\hline$\sigma_{c}^{2}$ & 0.0006 & 0.0007 & 0.0006 & 0.0006 & 0.0006 & 0.0006 & 0.0006 & 0.0006 \\
\hline$\sigma_{h}^{2}$ & 0.0100 & 0.0096 & 0.0095 & 0.0084 & 0.0086 & 0.0084 & 0.0084 & 0.0084 \\
\hline $\operatorname{corr}\left(u_{f}, u_{m}\right)$ & - & - & - & - & - & - & - & 0.23 \\
\hline $\boldsymbol{h}_{m}^{2}$ & $\begin{array}{c}0.0028 \\
(0.0011)\end{array}$ & - & $\begin{array}{c}0.0032 \\
(0.0011)\end{array}$ & - & $\begin{array}{c}0.0031 \\
(0.0011)\end{array}$ & - & $\begin{array}{c}0.0033 \\
(0.0011)\end{array}$ & $\begin{array}{c}0.0031 \\
(0.0010)\end{array}$ \\
\hline $\boldsymbol{h}_{f}^{2}$ & - & $\begin{array}{c}0.0500 \\
(0.0036)\end{array}$ & - & $\begin{array}{c}0.0525 \\
(0.0037)\end{array}$ & - & $\begin{array}{c}0.0527 \\
(0.0037)\end{array}$ & $\begin{array}{c}0.0523 \\
(0.0037)\end{array}$ & $\begin{array}{c}0.0523 \\
(0.0037)\end{array}$ \\
\hline Male repeatability & $\begin{array}{c}0.0072 \\
(0.0007)\end{array}$ & - & $\begin{array}{c}0.0084 \\
(0.0007)\end{array}$ & $\begin{array}{c}0.0097 \\
(0.0007)\end{array}$ & $\begin{array}{c}0.0081 \\
(0.0007)\end{array}$ & $\begin{array}{c}0.0081 \\
(0.0007)\end{array}$ & $\begin{array}{c}0.0082 \\
(0.0007)\end{array}$ & $\begin{array}{c}0.0082 \\
(0.0007)\end{array}$ \\
\hline Female repeatability & - & $\begin{array}{c}0.1089 \\
(0.0036)\end{array}$ & $\begin{array}{c}0.1368 \\
(0.0036)\end{array}$ & $\begin{array}{c}0.1131 \\
(0.0036)\end{array}$ & $\begin{array}{c}0.1063 \\
(0.0036)\end{array}$ & $\begin{array}{c}0.1131 \\
(0.0036)\end{array}$ & $\begin{array}{c}0.1115 \\
(0.0036)\end{array}$ & $\begin{array}{c}0.1115 \\
(0.0036)\end{array}$ \\
\hline
\end{tabular}

${ }^{1}$ Fixed effects included in the model: $\mathrm{M}=$ male effects (motility, dilution rate of the semen), $\mathrm{F}$ = female effects (age, synchronization on the previous year, total number of synchronizations during the female reproductive life, time interval between previous lambing and insemination, lactation status at time of insemination, milk quantity synchronizations during the female reproductive life, time interval between previous
produced during the previous year expressed as quartiles within each herd $\times$ year).

${ }^{2}$ Random permanent environmental effects included in the model: $\mathrm{M}=$ male effect, $\mathrm{F}=$ female effect.

${ }^{3}$ Genetic additive effects included in the model: $\mathrm{M}=$ male effect, $\mathrm{F}=$ female effect.

${ }^{4}$ Minus twice log-restricted maximum likelihood.

${ }^{5} P$-value of the restricted likelihood ratio test: models 3 vs. 1.

${ }^{6} P$-value of the restricted likelihood ratio test: models 4 vs. 2

${ }^{7} P$-value of the restricted likelihood ratio test: models 7 vs. 6 .

${ }^{8} P$-value of the restricted likelihood ratio test: models 7 vs. 5 .

${ }^{9} P$-value of the restricted likelihood ratio test: model 8 vs. 7 . 
nificant variation seems to exist among animals, the amplitude (symmetric interval, containing 99\% of the theoretical effects) of the genetic effect was $14 \%$ for male and $56 \%$ for female fertility, corresponding to the genetic coefficient of variation of 4 and $19 \%$ for male and female fertility, respectively. So, even if the male and female source of variation appeared small, the expected range of breeding value among extreme animals was not negligible.

The variance of the random inseminator effect was small in comparison with the herd $\times$ year effect nested within inseminator and was not significantly different from 0 . Nevertheless, the inseminator effect was kept in the model because it is known to affect the insemination result.

Our data set uniquely allowed matching male and female information for each insemination event. Even if many effects have been tested in this model, $83 \%$ of the initial variance remained unexplained in model 7 . A solution to explain insemination results better could be to record additional information. Other factors affecting variance of fertility are described in the literature. For example many tests of sperm morphology, particularly the acrosomal status (Saacke and White, 1972) and metabolism have been correlated with fertility (Foote, 2003). The nutritional deficit of the female has been viewed to influence the ability of the female to initiate and to sustain a pregnancy (Butler, 1998), and BCS is known to have a significant influence on fertility (Grimard et al., 2006). Recording new semen characteristics routinely is impossible in French AI centers, but recording some information on herd management may be realistic and could improve the explanation of fertility and increase estimates of heritabilities. Another solution could be to include nonadditive, fetal genetic effects in the model although we are not sure that this would decrease the residual variance a lot. Improving models could also be done in other ways. For instance, including motility, concentration (dilution) of the semen in the model assumes that motility and concentration themselves are not a heritable part of male fertility effects. This may not be true, and these effects might be taken into account through a recursive model (Gianola and Sorensen, 2004).

\section{CONCLUSIONS}

Repeated measurements of the insemination result, where each insemination was matched with several factors related to both sexes, were used to study male and female fertility traits. Due to the structure of this data there were no clear advantages from substituting the threshold model for the linear model. Moreover, including or ignoring information specific to one sex (fixed, environmental, and genetic effects) did not change results for fertility in the other sex. Genetic parameters remained nearly constant. Nevertheless, joint modeling of fertility is statistically the best model and could be upgraded to analyze interaction between sexes. These results also showed that, for French dairy sheep with regular use of AI, estimation of breeding values for male and female fertility might be implemented with quite simple models. However, the very small estimates of heritabilities indicate that efficiency of selection for these traits will be limited. Studies on genetic correlation with other traits such as semen production, whose genetic parameters are described in David et al. (2007), must be carried out to determine alternatives to indirect selection.

\section{ACKNOWLEDGMENTS}

The authors thank the ministère de l'Agriculture for supporting this study in the frame of a "BELIA action", directed by the ANIO and the INRA, and the AI centers who provided the data.

\section{REFERENCES}

Andersen-Ranberg, I. M., G. Klemetsdal, B. Heringstad, and T. Steine. 2005. Heritabilities, genetic correlations, and genetic change for female fertility and protein yield in Norwegian Dairy Cattle. J. Dairy Sci. 88:348-355.

Averill, T. A., R. Rekaya, and K. Weigel. 2004. Genetic analysis of male and female fertility using longitudinal binary data. J. Dairy Sci. 87:3947-3952.

Boichard, D., and E. Manfredi. 1994. Genetic analysis of conception rate in French Holstein cattle. Acta Agric. Scand. A Anim. Sci. 44:138-145.

Butler, W. R. 1998. Review: Effect of protein nutrition on ovarian and uterine physiology in dairy cattle. J. Dairy Sci. 81:2533-2539.

David, I., L. Bodin, G. Lagriffoul, E. Manfredi, and C. Robert-Granié. 2007. Character process model for semen volume in AI rams: Evaluation of correlation structures for long and short-term environmental effects. Genet. Sel. Evol. 39:55-72.

Donoghue, K. A., R. Rekaya, J. K. Bertrand, and I. Misztal. 2004. Threshold-linear analysis of measures of fertility in artificial insemination data and days to calving in beef cattle. J. Anim. Sci. 82:987-993.

Foote, R. H. 2003. Fertility estimation: A review of past experience and future prospects. Anim. Reprod. Sci. 75:119-139.

Gelman, A., and D. B. Rubin. 1992. Inference from iterative simulation using multiple sequences. Stat. Sci. 7:457-472.

Gianola, D. 1982. Theory and analysis of threshold characters. J. Anim. Sci. 54:1079-1096.

Gianola, D., and D. Sorensen. 2004. Quantitative genetic models for describing simultaneous and recursive relationships between phenotypes. Genetics 167:1407-1424.

Gilmour, A. R., B. J. Gogel, B. R. Cullis, S. J. Welham, and R. Thompson. 2002. ASReml User Guide Release 1.0. VSN International Ltd., Hemel Hempstead, UK.

Gonzalez-Recio, O., and R. Alenda. 2005. Genetic parameters for female fertility traits and a fertility index in Spanish dairy cattle. J. Dairy Sci. 88:3282-3289.

Grimard, B., S. Freret, A. Chevallier, A. Pinto, C. Ponsart, and P. Humblot. 2006. Genetic and environmental factors influencing first service conception rate and late embryonic/foetal mortality in low fertility dairy herds. Anim. Reprod. Sci. 91:31-44. 
Harville, D., and R. Mee. 1984. A mixed-model procedure for analyzing ordered categorical data. Biometrics 40:393-408.

Hoeschele, I., and B. Tier. 1995. Estimation of variance components of threshold characters by marginal posterior modes and means via Gibbs sampling. Genet. Sel. Evol. 27:519-540.

Kadarmideen, H. N., R. Thompson, and G. Simm. 2000. Linear and threshold model genetic parameters for disease, fertility and milk production in dairy cattle. Anim. Sci. 71:411-419.

Matos, C. A., D. L. Thomas, D. Gianola, M. Perez-Enciso, and L. D. Young. 1997a. Genetic analysis of discrete reproductive traits in sheep using linear and nonlinear models: I. Estimation of genetic parameters. J. Anim. Sci. 75:76-87.

Matos, C. A., D. L. Thomas, D. Gianola, M. Perez-Enciso, and L. D. Young. 1997b. Genetic analysis of discrete reproductive traits in sheep using linear and nonlinear models: II. Goodness of fit and predictive ability. J. Anim. Sci. 75:88-94.

Meijering, A., and D. Gianola. 1985. Linear versus nonlinear methods of sire evaluation for categorical traits: A simulation study. Genet. Sel. Evol. 17:115-131.

Morrell, C. H. 1998. Likelihood ratio testing of variance components in the linear mixed-effects model using restricted maximum likelihood. Biometrics 54:1560-1568.

Nadarajah, K., E. B. Burnside, and L. R. Schaeffer. 1988. Genetic parameters for fertility of dairy bulls. J. Dairy Sci. 71:2730-2734.

Piles, M., O. Rafel, J. Ramon, and L. Varona. 2005. Genetic parameters of fertility in two lines of rabbits with different reproductive potential. J. Anim. Sci. 83:340-343.

Ramirez-Valverde, R., I. Misztal, and J. K. Bertrand. 2001. Comparison of threshold vs linear and animal vs sire models for predicting direct and maternal genetic effects on calving difficulty in beef cattle. J. Anim. Sci. 79:333-338.

Ranberg, I. M. A., B. Heringstad, G. Klemetsdal, M. Svendsen, and T. Steine. 2003. Heifer fertility in Norwegian dairy cattle: Variance components and genetic change. J. Dairy Sci. 86:2706-2714.

Saacke, R. G., and J. M. White. 1972. Semen quality tests and their relationships to fertility. Pages $22-27$ in 4 th Tech. Conf. Artificial Insemination Reprod., Natl. Assoc. Anim. Breeders, Columbia, MO

SAS. 1999. SAS/STAT Software. Version 8 ed. SAS Institute Inc., Cary, NC.

Spangler, M. L., R. L. Sapp, R. Rekaya, and J. K. Bertrand. 2006. Success at first insemination in Australian Angus cattle: Analysis of uncertain binary responses. J. Anim. Sci. 84:20-24.

Varona, L., and J. L. Noguera. 2001. Variance components of fertility in Spanish Landrace pigs. Livest. Prod. Sci. 67:217-221.

Weigel, K. A., and R. Rekaya. 2000. Genetic parameters for reproductive traits of Holstein cattle in California and Minnesota. J. Dairy Sci. 83:1072-1080.

Wright, S. 1934. An analysis of variability in number of digits in an inbred strain of guinea pigs. Genetics 19:506-536.

\section{APPENDIX}

Under the threshold model assumptions, the insemination result is assumed to be determined by a threshold liability process involving a purely additive model on the underlying scale. The model assumed for the underlying variable $(l)$, was

$$
\begin{gathered}
l=X_{f} \beta_{f}+X_{m} \beta_{m}+X_{c} \beta_{c}+Z_{f} u_{f}+Z_{m} u_{m}+W_{f} p_{f} \\
+W_{m} p_{m}+K c+L h+\varepsilon
\end{gathered}
$$

where notations are the same as in model 8. The animal threshold model was fitted using the TM software developed by A. Legarra (INRA-SAGA, Castanet-Tolosan, France; personal communication). Flat priors were assumed for fixed effects and variance components. The Gibbs sampler analysis was carried out through 2 chains of 500,000 iterations each with different starting values. After discarding the first 50,000 iterations, samples of the parameters of interest were saved from every hundred iteration. Gelman and Rubin's diagnostic test was used to assess convergence (Gelman and Rubin, 1992). Statistics of marginal posterior distributions were directly calculated from the samples.

Trace plots (not shown) of different chains completely overlapped for all unknowns, suggesting convergence. Gelman-Rubin statistics were between 0.99 and 1 in all cases. Summary statistics of marginal posterior distribution of male and female genetic parameters are presented in Appendix Table 1. Heritability estimated under the p-scale was identical to the one obtained in the linear case for female fertility (about $5 \%$ ) and a little higher for male fertility $(0.66$ vs. $0.31 \%)$ but still near 0 .

Table A1. Summary statistics of marginal posterior distributions of genetic male and female parameters

\begin{tabular}{lcrcc}
\hline Item & $\mathrm{PM}^{1}$ & $5 \%^{2}$ & $50 \%^{2}$ & $95 \%^{2}$ \\
\hline $\boldsymbol{\sigma}_{\boldsymbol{p m}}^{\mathbf{2}}$ & 0.0061 & 0.0021 & 0.0061 & 0.0101 \\
$\boldsymbol{\sigma}_{\boldsymbol{u m}}^{\mathbf{2}}$ & 0.0109 & 0.0055 & 0.0107 & 0.0171 \\
$\boldsymbol{\sigma}_{\boldsymbol{p f}}^{\mathbf{2}}$ & 0.1190 & 0.1016 & 0.1196 & 0.1372 \\
$\boldsymbol{\sigma}_{\boldsymbol{u f}}^{\mathbf{2}}$ & 0.1098 & 0.0963 & 0.1094 & 0.1237 \\
$\boldsymbol{c o r r}\left(\mathbf{u}_{\boldsymbol{f}}, \boldsymbol{u}_{\boldsymbol{m}}\right)$ & 0.1413 & -0.0709 & 0.1432 & 0.3351 \\
$\boldsymbol{h}_{\boldsymbol{m}}^{\mathbf{2}}(\mathrm{x}-\mathrm{scale})^{3}$ & 0.0107 & 0.0054 & 0.0105 & 0.0168 \\
$\boldsymbol{h}_{\boldsymbol{f}}^{\mathbf{2}}(\mathrm{x} \text {-scale })^{3}$ & 0.0893 & 0.0787 & 0.0890 & 0.1001 \\
$\boldsymbol{h}_{\boldsymbol{m}}^{\mathbf{2}}(\mathrm{p} \text {-scale })^{3}$ & 0.0067 & 0.0034 & 0.0066 & 0.0105 \\
$\boldsymbol{h}_{\boldsymbol{f}}^{\mathbf{2}}(\mathrm{p} \text {-scale })^{3}$ & 0.0560 & 0.0494 & 0.0559 & 0.0629 \\
\hline
\end{tabular}

${ }^{1}$ Posterior mean.

${ }^{2} 5,50,95 \%=$ percentiles at 5,50 and $95 \%$.

${ }^{3} \mathrm{p}$-scale $=$ observed variate scale, $\mathrm{x}$-scale $=$ underlying variate scale, $\boldsymbol{h}_{(x-\text { scale })}^{2}=\sigma_{u}^{2} /\left(\sigma_{u}^{2}+\sigma_{p}^{2}+1\right), \boldsymbol{h}_{(p \text {-scale })}^{2}=\boldsymbol{h}_{(x-\text { scale })}^{2} \boldsymbol{z}^{2} /(\boldsymbol{p}(1-\boldsymbol{p}))$, where $\mathrm{p}$ is the probability of AI success, and $\mathrm{z}$ is the ordinate of a standard normal density function corresponding to a threshold $=\Phi^{-1}(\boldsymbol{p})$, where $\Phi$ is the cumulative distribution function of a standard normal variate. 